\title{
Opportunities regarding the potential use of the self-cleaning concept within urban contemporary architecture in Romania
}

\author{
Elvira Grebenișan ${ }^{1,2, *}$, Henriette Szilagyi ${ }^{1}$, Andreea Hegyi $^{1}$, Călin Mircea ${ }^{2}$, and Cornelia Baeră ${ }^{3}$ \\ ${ }^{1}$ N.I.R.D. URBAN-INCERC, Cluj-Napoca Branch, Romania \\ ${ }^{2}$ Technical University of Cluj-Napoca, Civil Engineering Faculty, Cluj-Napoca, Romania \\ ${ }^{3}$ N.I.R.D. URBAN-INCERC, Timişoara Branch, Romania
}

\begin{abstract}
Contemporary urban architecture faces two important issues: degradation of buildings, caused by exposure to various environmental factors (air and water pollution, mainly generated by the fuels combustion used for transport and heating) and also the costs for repair, cleaning and maintenance of the buildings facades. Regarding the last mentioned aspects, recent research led to development of materials with self-cleaning potential and consequently pollution reduction. Selfcleaning concrete represents a state-of-the-art material with photocatalytic properties generated by the addition in its composition of nanomaterials like $\mathrm{TiO}_{2}$. Already known for its intrinsic photocatalytic character, $\mathrm{TiO}_{2}$ has the ability to catalyse the decomposition of organic substances like grease and dirt, facilitating their quick removal only by rainwater action. Therefore, a building façade made of $\mathrm{TiO}_{2}-\mathrm{SiO}_{2}$-containing material develops substantial savings regarding maintenance costs, water consumption and less detergents contamination due to its intrinsic super hydrophilic effect of the surface in the presence of UV radiation, leading to easy dirt removal when water reaches it. The aim of present paper is presenting the latest stage of worldwide research regarding the obtaining of self-cleaning concrete and also the possibility of adapting the concept to the actual Romanian architecture needs, as a sustainable solution for urban pollution reduction.
\end{abstract}

\section{Introduction}

Nowadays the possibility of developing cementitious composites with self-cleaning properties is reported worldwide due to the photocatalytic properties of $\mathrm{TiO}_{2}$ nanoparticles, used as an addition or as a substitute for a part of cement, in the mix.

The photocatalytic substance is a material activated by the action of sunlight or UV radiation, causing an oxidation-reduction reaction Titanium dioxide, $\mathrm{TiO}_{2}$. This is a crystalline substance, with photocatalytic properties, that can be found in three forms of crystallization: anatase, rutile and brookite. Of all substances with photocatalytic properties, the use of $\mathrm{TiO}_{2}$ anatase has the following advantages: it proves a high chemical stability under the action of acids and bases, it is not toxic, it has a relatively low price and has the ability to decompose organic and inorganic substances into stable compounds, oxides / salts, neutralized, thus contributing to depollution, sterilization and unpleasant odour elimination. The most important property of $\mathrm{TiO}_{2}$, accidentally discovered in 1995 , was regarding a composition of $\mathrm{TiO}_{2}-\mathrm{SiO}_{2}$, which, in the presence of UV radiation revealed the effect of surface superhydrophilicity. Another important feature of the $\mathrm{TiO}_{2}-\mathrm{SiO}_{2}$ compositions is that, unlike $\mathrm{TiO}_{2}$ whose photocatalytic activity ceases without UV radiation, the photocatalytic effect continues hours, even days after removal of the UV source. The combination of these two photo-induced properties (photocatalytic and superhydrophilicity) is the basic mechanism of selfcleaning cementitious materials, with antibacterial, depollution, water and air purification properties [1]. In 1997, Luigi Cassar et al. present the first official publication related to the manufacture of cement materials with the self-cleaning property [2], [3].

The first experimental attempts in the topic of selfcleaning materials were performed by using enriched $\mathrm{TiO}_{2}$ in white cement compositions. In 1996, the first relevant results were reported and in 2003 the first largescale construction of this kind, the church Dives in Misericordia, Rome, was put into use (Fig. 1) [5].

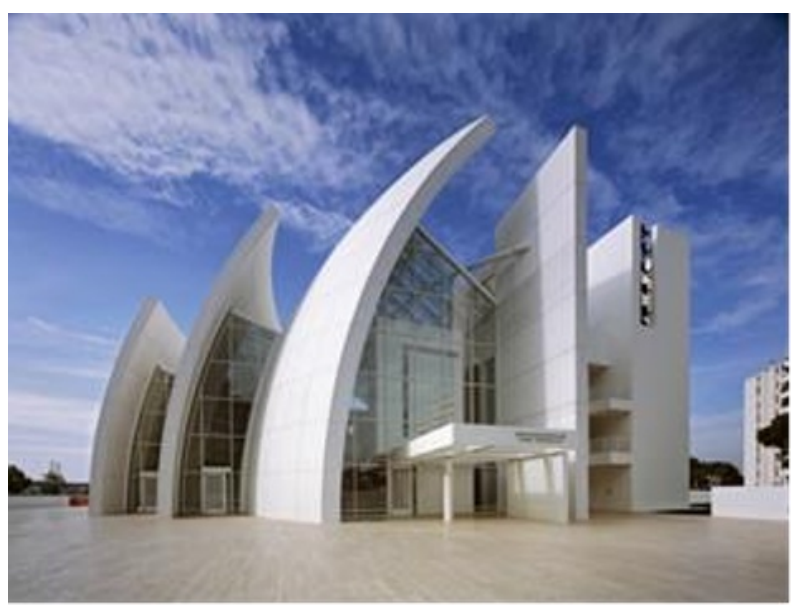

Fig. 1. The church Dives in Misericordia, Rome, Italy 
Some reports have indicated that up to 2003, approximately 5000 constructions in Japan have used cementitious composites enriched with $\mathrm{TiO}_{2}$ nanoparticles [4]. The latest use of this composite material was to build the famous Palazzo Italia Expo 2015, Milan, Italy. The purpose of this paper is to present the latest stage of global research on concrete with self-cleaning properties and to adapt the concept to the current needs of Romanian architecture, as a sustainable solution for reducing urban pollution.

\section{Design and realization of cement composite materials with $\mathrm{TiO}_{2}$ nanoparticles}

Titanium dioxide has been used in the field of construction to induce the self-cleaning ability of various building elements, namely: building facades, exterior tiles, finishing coatings, road blocks, concrete pavements, etc., due to its chemical stability and compatibility with traditional building materials [6].

Three technologies for exploiting the properties of $\mathrm{TiO}_{2}$ nanoparticles are currently known and used: surface coatings with $\mathrm{TiO}_{2}$ dispersion solutions, surface coatings with a superficial cementitious composite layer including $\mathrm{TiO}_{2}$ and the realization of entire concrete elements with $\mathrm{TiO}_{2}$. According to the studies reported in the literature, the best photocatalytic efficiency is the introduction of nanoparticles in superficial layer, without vibration [7]. Generally, the literature recommends that the $\mathrm{TiO}_{2}$ nanoparticles to be initially added and dried mixed to the cement, followed by the addition of hydration water. It does not chemically react with any crystallographic form of titanium dioxide, nor does a reaction occur between the photosensitive nanoparticles with the cement phases, therefore the hydrolysis hydration reactions are not influenced [1].

The particle size and distribution of the $\mathrm{TiO}_{2}$ powder was proved to influence the cementitious composite material; consequently, at the University of Milan, Italy, research was carried out by using $\mathrm{TiO}_{2}$ powders with micrometric dimensions $\left(\mathrm{m}-\mathrm{TiO}_{2}\right)$ or nanometric dimensions $\left(\mathrm{n}-\mathrm{TiO}_{2}\right)$ [1]. The obtained results showed that there are advantages and disadvantages in both cases. Thus, dispersion and distribution in the matrix is more convenient for the use of micrometric-sized granules as the nanometric ones tend to agglomerate, thereby reducing the total reactive surface available for photocatalytic reactions initiation. On the other hand, the use of nanoscale granules is advantageous, albeit more difficult, because the composite would have a better adsorption capacity of pollutant oxides, which can easily penetrate the nanoparticle agglomerations. The research carried out so far has not revealed a defining influence of particle size granulometry on the efficiency of the cement matrix enriched with $\mathrm{TiO}_{2}$, from the point of view of the decomposition capacity of the polluting molecules and the dirt particles. Thus, it would be preferable to use nanoscale particles as they sum up both, the more efficient decomposition effect of the pollutant particles of the type of nitrogen oxides as well as their superhydrophilicity, thus decreasing the contact angle of the water and creating a uniform water film on the treated surfaces [8]. This prevents the contact between the external dirt and the surface itself, thus facilitating the washing of the pollutants and dirt particles. However, the influence of photoactivation light is neglected, because studies showed that there are differences even in the case of keeping all the initial preparation parameters, if the preparation of the composite takes place in artificial light, natural or dark light or in the same type of light but with different intensities [1], [9].

The unanimous conclusion is that, for each case, it is necessary to determine the optimum quantity of $\mathrm{TiO}_{2}$ nanoparticles used in the composite; an additional amount of $\mathrm{TiO}_{2}$ is not economic and very often it can negatively influence some parameters of the cement composite matrix enriched with nanoparticles $\mathrm{TiO}_{2}$. It is also considered that, in most cases, the enrichment with $\mathrm{TiO}_{2}$ nanoparticles of the entire mass of the concrete element is not necessary; a coating layer of composite material with photocatalytic properties is proved to be sufficient to increase element durability and to achieve the environmental purification effect.

\section{Performance of cement composite materials with $\mathrm{TiO}_{2}$ nanoparticles, in fresh concrete}

A series of investigations to date have highlighted that introducing the $\mathrm{TiO}_{2}$ nanoparticles influences the properties of fresh concrete. The first observed effect in preparing of cement mortar and concrete is the increase in water demand to achieve the standard consistency [4]. Regarding the influence of the used amount of $\mathrm{TiO}_{2}$ nanoparticles, considering the workability point of view of, it can be said that increasing it leads to clear decrease of workability. This effect was noticed in both, simple cement paste mixes and also in composites containing slag. Thus, the sequence of used content (percentage) of nanoparticles of titanium dioxide $\left(\mathrm{TiO}_{2}\right)$ was: 0 and $2.0 \% ; 0,0.5,1.0,1.5$ and $2.0 \% ; 0,1.0$ and $3.0 \% ; 0,1.0$, 3.0 and $5.0 \%$; and $0,1.0,2.0,3.0,4.0$ and $5.0 \%$, in simple cement systems (Fig. 2), respectively $0,5.0$ and $10.0 \%$ in composite systems mixed with slag [6]. However, some research has indicated that cement replacement with a maximum of $1.0 \% \mathrm{TiO}_{2}$ (by weight), does not significantly affect the fluidity of the cement mortar, independently of slag adding or not to the mix [10].

When introducing different amounts of $\mathrm{TiO}_{2}$ nanoparticles (like: $0,5.0$ and $10.0 \% ; 0,0.5,1.0,1.5$ and $2.0 \% ; 0,5.0,7.0$ and $10.0 \%$ ), it was observed that initial and final open time decreased with increasing the content of $\mathrm{TiO}_{2}$ nanoparticles [6]. (Fig. 3).

The decrease in both, workability and open time with the increase in the amount of $\mathrm{TiO}_{2}$ nanoparticles introduced into the cement paste can be explained by the catalytic effect of the nanoparticles on the cement hydration reaction and they function as potential storage cores of hydration products. 


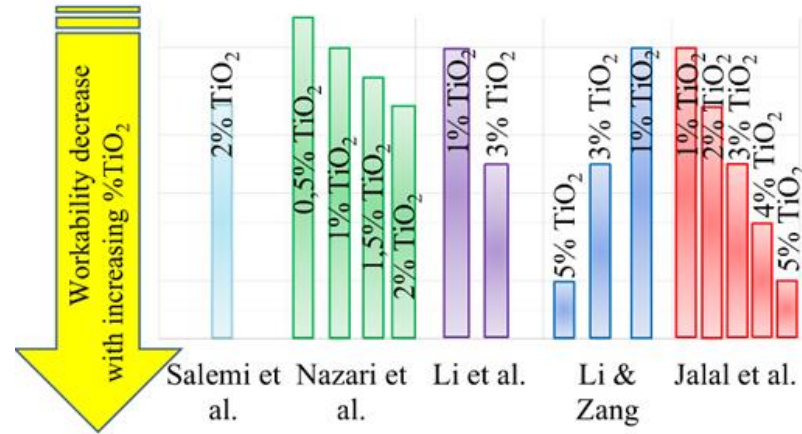

Fig. 2. Workability decreasing with increasing of $\mathrm{TiO}_{2}$ content [processing reference 6]

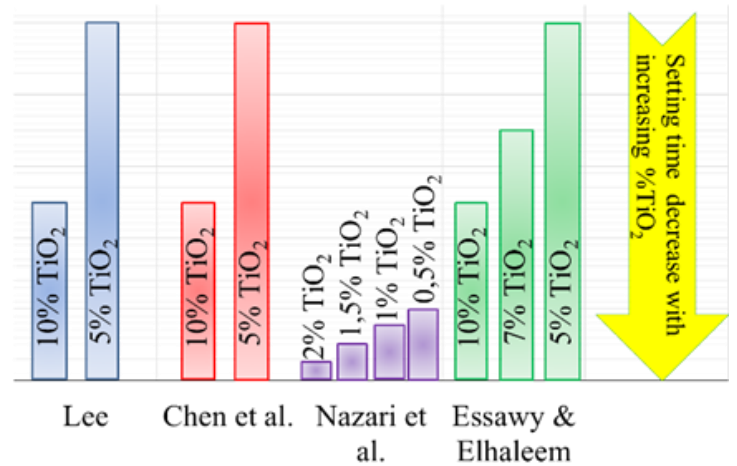

Fig. 3. Setting time decreasing with increasing of $\mathrm{TiO}_{2}$ content [processing reference 6]

Research on matrix hardening processes has revealed significant increase of the hydration heat together with increase of the cement hydration rate [4], [10], the change of the structural orientation of the $\mathrm{CH}$ crystals and of their dimensions, as well [4]. Figure 4 shows the growth rate of the cement hydration heat for the pastes where different content (percent by weight) of $\mathrm{TiO}_{2}$ nanoparticles added. Figure 5 emphasises the increase rate of the heat released by hydration for cement pastes with slag addition and various $\mathrm{TiO}_{2}$ nanoparticles content.

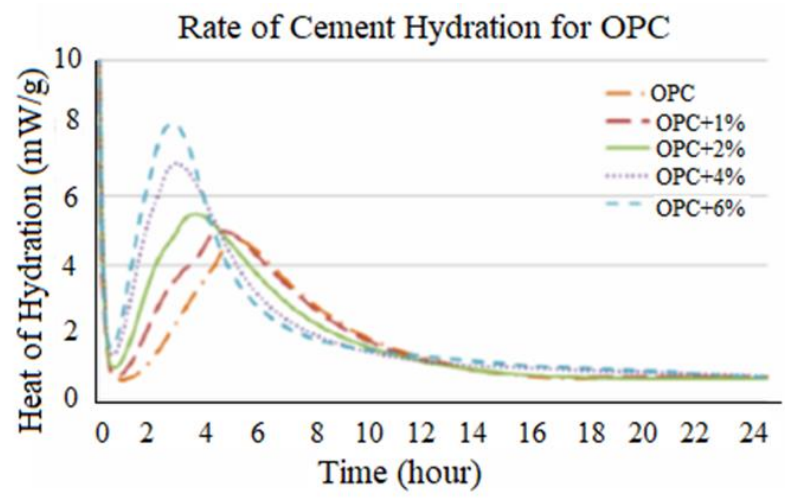

Fig. 4. Rate of heat release evolution for Portland cement pastes with different $\mathrm{TiO}_{2}$ dosages [11]
Rate of Cement Hydration for $50 \%$ OPC \& $50 \%$ slag

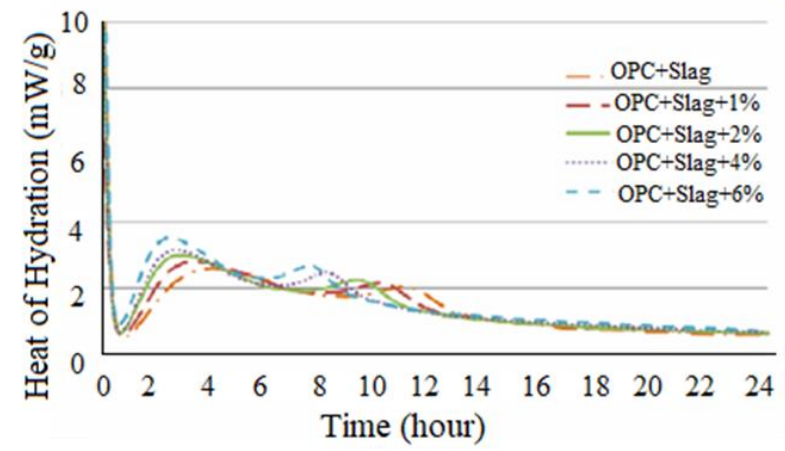

Fig. 5. Rate of heat release for cement pastes with $50 \%$ Slag and different $\mathrm{TiO}_{2}$ dosages [11]

\section{Self-cleaning performance of cementitious composite materials with $\mathrm{TiO}_{2}$ nanoparticles in hardened concrete}

According to the research done so far, in terms of the durability of the self-cleaning property as well as the overall durability of the composites, it is appreciated that the light wavelength in the visible field is sufficient to induce the photoactivation of $\mathrm{TiO}_{2}$, but it may lead to colouring, sensitization and colour degradation through this mechanism [1]. For photoactivation is generally preferable to select waves in the UV field around the wavelength of $360 \mathrm{~nm}$. The degradation mechanisms vary function to the wavelength at the time of preparation, and function to illumination amount during conditioning [1]. A large number of experimental studies have shown that compressive strength increases with increasing the nanoparticles content, the optimum content being of $1 \%$. Other studies claimed that compressive strength decreases as the $\mathrm{TiO}_{2}$ content increases [6]. (Fig. 6).
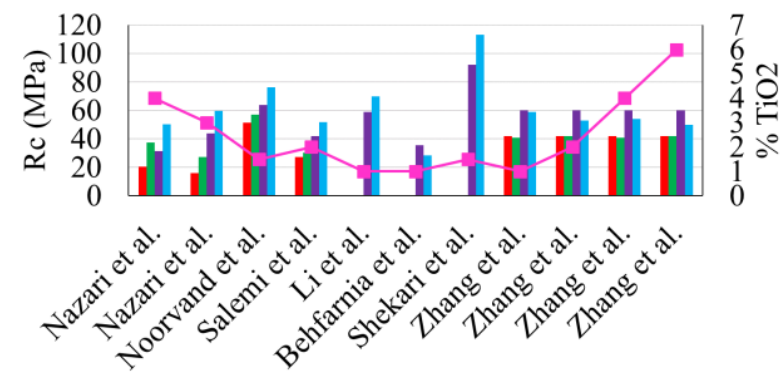

$\square$ Rc blank sample 7 days $\square$ Rc sample 7 days

$\square$ Rc blank sample 28 days $\square$ Rc sample 28 days 글 $\% \mathrm{TiO} 2$

Fig. 6. Influence of $\mathrm{TiO}_{2}$ on compressive strength [processing references $6,11,12$ ]

Concrete containing $\mathrm{TiO}_{2}$ nanoparticles showed less increase in compressive strength over 7 to 28 days compared to control concrete, as shown in Figure 7. 


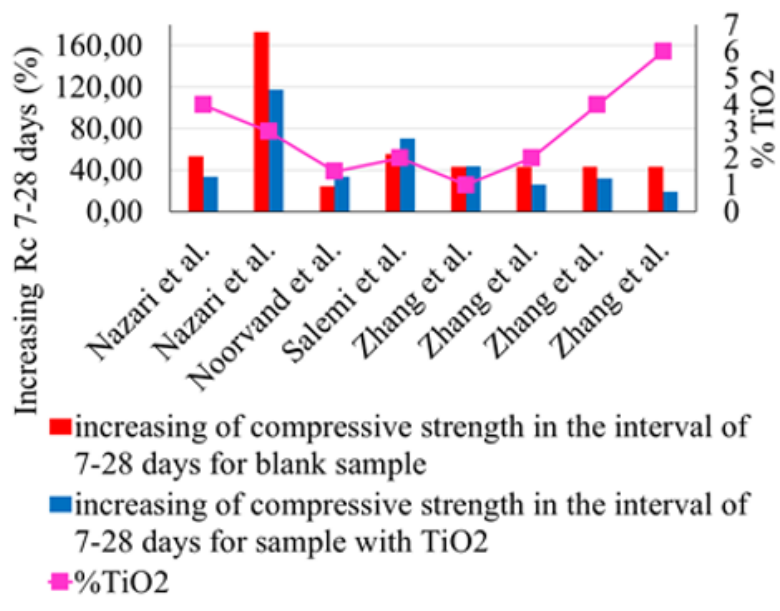

Fig. 7. Influence of $\mathrm{TiO}_{2}$ on the increase of compressive strength in the interval of 7-28 days [processing references 6, $11,12]$

According to the literature, the early age compressive strength growth rate was higher than at older ages. Consequently, $5 \%$ (by weight) of $\mathrm{TiO}_{2}$ nanoparticles introduced in the mixes increased the compressive strength 1,3 and 7 days but it reduced it at the age of 28 days, at a water to binder $(\mathrm{w} / \mathrm{b})$ ratio of 0.5 . A $10 \% \mathrm{TiO}_{2}$ nanoparticle addition increased the compressive strength at 1 and 7 days but it reduced it at 3 and 28 days, at a water to binder $(\mathrm{w} / \mathrm{b})$ ratio 0.5 . Considering a $0.4 \mathrm{w} / \mathrm{b}$ ratio, the compressive strength increases along with the $\mathrm{TiO}_{2}$ nanoparticles content increasing; considering the $\mathrm{w} / \mathrm{b}$ ratio of 0.5 or 0.6 , the compressive strength decreases with the content increase of $\mathrm{TiO}_{2}$ nanoparticles [6].

In terms of flexural strength, the use of $1.0 \%$ and $3.0 \% \mathrm{TiO}_{2}$ nanoparticles addition in relation to the amount of cement, increased the flexural strength, while a $5 \%$ addition decreased it. The optimum $\mathrm{TiO}_{2}$ nanoparticles addition was considered to be $1 \%$ (by weight, related to the cement content). Splitting and flexural strength increased with increasing the $\mathrm{TiO}_{2}$ nanoparticles addition; 4\% is considered the optimum percentage. High flexural and splitting resistances are also reported by other authors who established that the optimal percentage of $\mathrm{TiO}_{2}$ nanoparticles is $1 \%$ for water curing and $2 \%$ for limewater curing [6]. In literature, the increase of fatigue strength is experimentally confirmed, $1 \%$ being the optimum $\mathrm{TiO}_{2}$ nanoparticles addition. Cement composites developed with $10 \%$ slag addition and $\mathrm{TiO}_{2}$ nanoparticles additions of $5 \%$ and respectively $10 \%$ (cement related content) led to compressive strength increase at 1 day and induced a decrease of the compressive strength at 28 days. Increase of the flexural strength also occurs for the mixtures containing $45 \%$ slag and $3 \% \mathrm{TiO}_{2}$ nanoparticles [6].

The increase of $\mathrm{TiO}_{2}$ nanoparticles leads to the chlorine permeability coefficient reduction, the optimum content of nanoparticles addition being $1 \%$, according to the reports made by some authors, and $4 \%$ being the optimal addition of nanoparticles according to experimental researches carried out by others [6].
Simultaneously with the increase of the amount of $\mathrm{TiO}_{2}$ nanoparticles used in mix, the porosity reduction occurs. Water absorption of the composite, determined at the age of 28 days and 90 days, showed that increasing the nanoparticles content reduces the water absorption, $0.5 \%$ being the optimum addition content of $\mathrm{TiO}_{2}$ nanoparticles. For water absorption evaluated at the age of 7 days, the $4 \% \mathrm{TiO}_{2}$ nanoparticle content is proved to develop the best results. However, in all cases, if water absorption is evaluated at the age of 2 days, the addition of $\mathrm{TiO}_{2}$ nanoparticles tents to reduce it. In terms of aesthetic durability, experimental research has shown that keeping white or coloured (in the case of coloured matrix) is not influenced by the amount of nanoparticles addition. $\mathrm{TiO}_{2}$ particles are characterized by a high degree of whiteness, but their relatively uniform mass distribution does not affect the possibility of staining using classical pigments. Once the composite mass was coloured, no time fades were observed due to the photocatalytic activity of $\mathrm{TiO}_{2}$ nanoparticles [1].

\section{Environmental influence of self- cleaning building}

Although the influence of $\mathrm{TiO}_{2}$ nanoparticles on the properties of fresh and reinforced concrete still has many uncertainties, the antibacterial, antimicrobial and antifungal effect of $\mathrm{TiO}_{2}$, for some of the most common microorganisms (cladophora, chlorella vulgaris, escherichia coli, aspergillius niger), is analysed and proved [13]. Thus, $\mathrm{TiO}_{2}$ enriched cement materials became an ally in the fight for disinfection, sterilization and purification of surfaces, water and air from sensitive public spaces (hospitals, schools, restaurants, airports, etc.). Therefore, a significant number of studies has demonstrated the ability of this semiconductor to decompose organic substances, grease and dirt, making them to be easily rainwater washed [4], [8]. Since the $\mathrm{TiO}_{2}$ cement material surface is superhydrophilic (water no longer forms droplets but lamellas instead, which are able to easily remove decomposed compounds), the washing process is clearly more facile. Moreover, surfaces retain and regenerate their aesthetic appearance and colour under the action of UV radiation [4]. Thus, some authors reported that tests performed on $1 \%, 2 \%$, $4 \%$ or $6 \% \mathrm{TiO}_{2}$ concrete surfaces indicated the selfcleaning capacity preservation even after continuous exposure to UV for 1500 hours [11]. Therefore, because of the self-cleaning capacity of these kind of surfaces, the water and detergent consumptions are reduced.

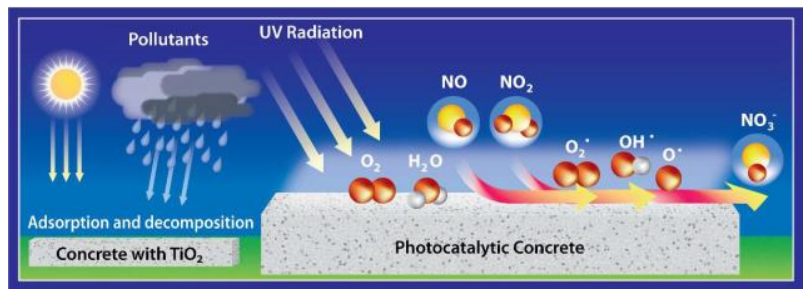

Fig. 8. Schematic of photocatalytic air purifying pavement [14] 
Regarding the air pollution, Luigi Cassar called the concrete with $\mathrm{TiO}_{2}$ "smog-eating concrete" [2]. In urban areas air pollution is mainly caused by combustion of heating and transport fuels, so the most frequent pollutants are $\mathrm{CO}, \mathrm{NOx}, \mathrm{VOC}$ and dust. The research results have shown that $\mathrm{TiO}_{2}$ contributes to the elimination of $\mathrm{CO}, \mathrm{NO}_{\mathrm{x}}, \mathrm{SO}_{\mathrm{x}}, \mathrm{NH}_{3}$, aromatic hydrocarbons, VOC [8], [15]. There are authors who believe that surfaces of cementitious materials enriched with $\mathrm{TiO}_{2}$ nanoparticles, as a result of their selfdecontamination capability, represents passive forms of safety technology to increase safety of biological, radiological and nuclear accidents. Regarding to this respect, the authors recommend the use of cementitious materials enriched with $\mathrm{TiO}_{2}$ nanoparticles for strategic military structure projects as well. The travertine durability, due to its efficient surface treatment by using a suspension of $\mathrm{TiO}_{2}$, has been demonstrated. Thus, when exposing the travertine surface, previously $\mathrm{TiO}_{2}$ cured, to the action of $\mathrm{H}_{2} \mathrm{~S}$, this is converted into $\mathrm{H}_{2} \mathrm{SO}_{4}$ by the means of the photocatalysis process and then it is eliminated by evaporation [16].

Experimental research has shown that the reduction in pollution by the absorption of nitrogen oxides, sulphur, etc., and the decomposition of larger pollutants (fats, oils, dusts, microorganisms) are also influenced by the light exposure conditions, meaning the number of hours of illumination, air traffic, traffic conditions, concentration and type of pollutants. Thus, in southern Europe where the climate and lighting conditions are very favourable, the degree of absorption of nitrogen oxides can reach up to $60 \%$. Under these conditions, namely the favourable lighting, an efficiency of $78( \pm 2)$ $\%$ has also been recorded for the toluene removal (with a considerable speed of $100 \mathrm{mg} / \mathrm{h}^{*} \mathrm{~m}^{2}$ ), when compared to less favourable regions, from the lightning and climatic point of view. [1].

\section{Standardization}

Due to the already proven benefits of $\mathrm{TiO}_{2}$ nanoparticulate concrete, some specific analysis methods for material evaluation have already been standardized over the past 15 years, as shown in Table 1 . It is noted that most of these are Japanese and Italian national standards, some being internationally assimilated.

Table 1. Standards for methods of analyzing the photocatalytic action of $\mathrm{TiO}_{2}[15]$

\begin{tabular}{|l|l|l|}
\hline $\begin{array}{l}\text { Performance } \\
\text { attributes }\end{array}$ & $\begin{array}{l}\text { Principle of test } \\
\text { method }\end{array}$ & Standard \\
\hline \multirow{4}{*}{$\begin{array}{l}\text { Air } \begin{array}{l}\text { purification } \\
\text { effect }\end{array} \\
\text { Nitric oxide }\end{array}$} & $\begin{array}{l}\text { JIS R 1701-1:2004 } \\
\text { UNI 11247:2007 } \\
\text { removal 22197-1:2007 }\end{array}$ \\
\cline { 2 - 3 } & $\begin{array}{l}\text { Removal Volatile } \\
\text { Organic Compound } \\
\text { (VOC) }\end{array}$ & $\begin{array}{l}\text { UNI 11238-1, } \\
2: 2007\end{array}$ \\
\cline { 2 - 3 } & $\begin{array}{l}\text { Acetaldehyde } \\
\text { removal }\end{array}$ & JIS R 1701-2:2008 \\
\cline { 2 - 3 } & ISO/CD 22197-2 \\
\hline
\end{tabular}

\begin{tabular}{|l|l|l|}
\hline $\begin{array}{l}\text { Performance } \\
\text { attributes }\end{array}$ & $\begin{array}{l}\text { Principle of test } \\
\text { method }\end{array}$ & Standard \\
\hline $\begin{array}{l}\text { Water } \\
\text { purification } \\
\text { effect }\end{array}$ & $\begin{array}{l}\text { Active oxygen- } \\
\text { forming }\end{array}$ & $\begin{array}{l}\text { JIS R 1704:2007 } \\
\text { ISO 10676: 2010 }\end{array}$ \\
\hline \multirow{4}{*}{$\begin{array}{l}\text { Self-cleaning } \\
\text { effect }\end{array}$} & $\begin{array}{l}\text { Water contact angle } \\
\text { change }\end{array}$ & $\begin{array}{l}\text { JIS R 1703-1:2007 } \\
\text { ISO 27448: 2009 }\end{array}$ \\
\cline { 2 - 3 } & $\begin{array}{l}\text { Methylene blue } \\
\text { decomposition }\end{array}$ & $\begin{array}{l}\text { JIS R 1703-2:2007 } \\
\text { ISO 10678:2010 }\end{array}$ \\
\cline { 2 - 3 } Rhodamine & UNI 11259:2008 \\
\hline \multirow{2}{*}{$\begin{array}{l}\text { Biocidal } \\
\text { effect }\end{array}$} & $\begin{array}{l}\text { Antibacterial } \\
\text { activity }\end{array}$ & $\begin{array}{l}\text { JIS R 1702:2006 } \\
\text { ISO 27447:2009 }\end{array}$ \\
\cline { 2 - 3 } Antifungal activity & JIS R 1705:2008 \\
\hline \multirow{2}{*}{ Other } & $\begin{array}{l}\text { Light source for test } \\
\text { under } \\
\text { irradiation }\end{array}$ & $\begin{array}{l}\text { JIS R 1709:2007 } \\
\text { ISO 10677: 2011 }\end{array}$ \\
\hline
\end{tabular}

\section{Conclusions}

Today the use of $\mathrm{TiO}_{2}$ nanoparticles is performed either by coating surfaces with $\mathrm{TiO}_{2}$ dispersion solutions or by coating surfaces with a superficial cementitious composite layer with $\mathrm{TiO}_{2}$ addition or by entirely producing elements of concrete with $\mathrm{TiO}_{2}$. The latter case is the least favourable, from the point of view of the high consumption of nanoparticles, some of which remaining unexploited due to their inherent positioning in the depth of the composite mass.

The purpose of this paper was to present the latest stage of global research on concrete with self-cleaning properties and to consider some possibilities for adapt the concept to the current needs of Romanian architecture, as a sustainable solution for reducing urban pollution. On the basis of the above it can be said that:

$\mathrm{TiO}_{2}$ nanoparticles have water and air purification properties, antimicrobial, antifungal and anti-allergic in the presence of UV.

- Under the action of UV rays, a $\mathrm{TiO}_{2}-\mathrm{SiO}_{2}$ composition becomes superhydrophilic, so that the water that reaches the surface of this material, as a result of the oxidation-reduction reaction, forms the lamellae which facilitate the uptake of the impurities, the photocatalytic effect continuing hours even days after removal of the source UV.

Activated by UV rays, the $\mathrm{TiO}_{2}$ nanoparticles facilitate the decomposition of organic pollutants (fats, oils, aromatic hydrocarbons) into simpler compounds, easily washable by rainwater; they also entrain the dust particles deposited on the superhydrophilic surface.

UV-activated $\mathrm{TiO}_{2}$ nanoparticles convert inorganic pollutants such as nitrogen, sulphates, acids, air, water or solids into oxide compounds / salts by oxidation reduction / neutralization reactions into stable compounds, oxides / salts, thus contributing both, in the self-cleaning of urban buildings and in the depollution.

In the fresh concrete the $\mathrm{TiO}_{2}$ nanoparticles reduce the workability, open time and porosity.

In terms of reinforced concrete performance: increased mechanical strength, increased frost-freeze resistance, increased resistance to abrasion and increased 
resistance of concrete to chemical agents, when the optimum $\mathrm{TiO}_{2}$ nanoparticles addition is used.

The influence of nanoparticles on the mechanical strengths of concrete is still controversial, but it can be already established that the first requirement is, on a case-by-case basis, the determination of the optimum $\mathrm{TiO}_{2}$ nanoparticles content, with respect to the cement.

The literature reports agree on the beneficial effect of $\mathrm{TiO}_{2}$ nanoparticles regarding the reduction of water and air pollution and on their self-cleaning capacity, despite the fact the mechanisms are not yet fully elucidated.

Over the past 15 to 20 years, research regarding cementitious composite matrixes with $\mathrm{TiO}_{2}$ addition has increased. as a direct result of the interest in achieving sustainable, aesthetic, low maintenance and improved performance, as well as identifying pollution reduction possibilities.

The optimal compositions of nanoparticles as well as the optimal granulometric distribution for the maximum benefits from the photocatalytic effect are not yet fully identified. On the other hand, even the photocatalytic activation mechanisms are not yet fully elucidated.

Since 2007 there were implemented some standardized methods of analysis in this topic and the trend of international assimilation is noticed.

\section{References}

1. A. Folli, $\mathrm{TiO}_{2}$ photocatalysis in Portland cement systems: fundamentals of self-cleaning effect and air pollution mitigation, $\mathrm{PhD}$ Thesis, University of Milan, Italy (2010)

2. L. Cassar, Nanotechnology and photocatalysis in cementitious materials, NICOM'2, Bilbao (2005)

3. A. Mujkanović, D. Bečirhodžić, N. Merdić, SelfCleaning Concrete - A construction material for building cleaner world, 20th International Research/Expert Conference "Trends in the Development of Machinery and Associated Technology" (2016), pp. 93-96

4. M. Janus, K. Zając, Concretes with Photocatalytic Activity, High Performance Concrete Technology and Applications, INTECH (2016)

5. Richard Meier \& Parteners Arhitects LLP: Jubilee Church, https://www.richardmeier.com, accessed in July 2019

6. A.M. Rashad, A synopsis about the effect of nanotitanium dioxide on some properties of cementitious materials - a short guide for civil engineer, Rev. Adv. Mater. Sci. 40 (2015), pp. 72-88

7. S. Hanson, Evaluation of concrete containing photocatalytic titanium dioxide, $\mathrm{PhD}$ Thesis Department of Civil and Environmental Engineering, The University of Utah (2014)

8. E. Quagliarini, F. Bondioli, G.B. Goffredo, C. Cordoni, P. Munafò, Self-cleaning and de-polluting stone surfaces: $\mathrm{TiO}_{2}$ nanoparticles for limestone,
Construction and Building Materials 37 (2012), pp. 51-57

9. D.H. Chen, K. Li, Photocatalytic Coating on Road Pavements/Structures for NOx Abatement, Annual Project Report Submitted to Houston Advanced Research Center and Office of Air Quality Planning and Standards U.S. Environmental Protection Agency Research Triangle Park, NC 27711 (2007)

10. J.V. Sorathiya, S.G. Shah, S.M. Kacha, Effect on Addition of Nano "Titanium Dioxide" $\mathrm{TiO}_{2}$ on Compressive Strength of Cementitious Concrete, International Conference on Research and Innovations in Science, Engineering \& Technology At: Birla Vishvakarma Mahavidyalaya, Gujarat, India 1 (2017)

11. S.M.-H. Zhang, D. Tanadi, W. Li, Effect of photocatalyst $\mathrm{TiO}_{2}$ on workability, strength, and self - cleaning efficiency of mortars for applications in tropical environment, 35th Conference on Our World in Concrete and Structures, Singapore (2010)

12. A. Hegyi, A. Lăzărescu, C. Dico, H. Szilagyi, The effect of $\mathrm{TiO}_{2}$ on the properties of cementitious composite materials - the current state-of-the art, Proceedings of the 18th International Multidisciplinary Scientific GeoConference \& EXPO - SGEM 2018, Albena, Bulgaria (2018), pp. 391-398

13. B. Ma, H. Li, J. Mei, X. Li, F. Chen, Effects of Nano-TiO ${ }_{2}$ on the Toughness and Durability of Cement-Based Material, Advances in Materials Science and Engineering (2015)

14. Boonen E., Beeldens A.: Recent Photocatalytic Applications for Air Purification in Belgium, Coatings (2014), 4, pp. 553-573

15. Y. Ohama, D. Van Gemert, Applications of Titanium Dioxide Photocatalysis to Construction Materials. State-of-the-Art Report, Ed. Springer (2011)

16. A. Sassolini, A. Malizia, F. D’Amico, M. Carestia, D. Di Giovanni, O. Cenciarelli, C. Bellecci, P. Gaudio, Evaluation of the effectiveness of titanium dioxide $\left(\mathrm{TiO}_{2}\right)$ self-cleaning coating for increased protection against cbrn incidents in critical infrastructures, Defence Science and Technical Bulletin 7 (2014), pp. 9-17 